\title{
Paracorporeal pulsatile biventricular assist device versus extracorporal membrane oxygenation-extracorporal life support in adult fulminant myocarditis
}

\author{
Olivier N. Pages, MD, ${ }^{\mathrm{a}}$ Stéphane Aubert, MD, ${ }^{\mathrm{a}}$ Alain Combes, MD, PhD, ${ }^{\mathrm{b}}$ Charles E. Luyt, MD, ${ }^{\mathrm{b}}$ Alain Pavie, MD, PhD, \\ Philippe Léger, $\mathrm{MD},{ }^{\mathrm{c}}$ Iradj Gandjbakhch, $\mathrm{MD}, \mathrm{PhD},{ }^{\mathrm{a}}$ and Pascal Leprince, $\mathrm{MD}, \mathrm{PhD}^{\mathrm{a}}$
}

\begin{abstract}
Objective: Biventricular assist device support with a paracorporeal pulsatile device is known to be an efficient bridge to recovery for patients with fulminant myocarditis-related cardiogenic shock. Whether these patients can be as efficiently supported with femorofemoral extracorporeal membrane oxygenation remains unclear.
\end{abstract}

\begin{abstract}
Methods: From 2001 to 2006, 11 patients were referred to our cardiac surgery department for fulminant myocarditis-related cardiogenic shock. The first 5 patients (mean age, $32 \pm 2$ years) were supported with a biventricular assist device (Thoratec, Pleasanton, Calif; group I), whereas the remaining patients (40 \pm 4 years) were supported with femorofemoral extracorporeal membrane oxygenation (group II). Preimplantation probability of death was calculated by using the APACHE II score, which was $11 \pm 9$ in group I versus $24 \pm 18$ in group II.
\end{abstract}

Results: One patient in each group died while receiving support. In group I the death occurred after 18 days of support in a patient who had 45 minutes of external resuscitation before biventricular assist device implantation. In group II a patient who remained unstable during extracorporeal membrane oxygenation was switched to a biventricular assist device 13 days later and eventually died of tamponade after 45 days. All other patients were weaned from the device after a mean duration of support of $21 \pm 5$ days in group I versus $13 \pm 4$ days in group II. At hospital discharge, the mean ejection fraction was $45 \% \pm 5 \%$ in both groups, and at 6 months' follow-up, it was $65 \%$ and $75 \%$, respectively, in groups I and II.

Conclusion: In our experience extracorporeal membrane oxygenation is as efficient as use of a biventricular assist device as a bridge to recovery for patients with fulminant myocarditis-related cardiogenic shock and facilitates renal and hepatic recovery on support.

Complete recovery of myocardial function is possible after fulminant myocarditis (FM) in the adult by using mechanical support as a bridge to recovery. ${ }^{1}$ Acker, ${ }^{2}$ in 2001 , reviewed the literature comparing different types of mechanical support. He found that survival by bridge to transplantation or to recovery should approach $70 \%$ and then strongly recommended an aggressive approach to use of biventricular mechanical support.

In the setup of FM, Leprince and colleagues, ${ }^{3}$ in 2003 , recommended the use of a biventricular assist device (BIVAD) during cardiopulmonary bypass on the beating heart. However, during the most recent years, extracorporeal membrane oxygenation (ECMO)-extracorporal life support was revealed as a precious cardiac support method used to stabilize emergency patients with severe cardiac dysfunction. The first results were very encouraging, and ECMO

From Institut de Cardiologie, Service de Chirurgie Thoracique et Cardiovasculaire ${ }^{\mathrm{a}}$; Institut de Cardiologie, Service de Réanimation Médicale ${ }^{\mathrm{b}}$; and Département d'Anesthésie Réanimation, ${ }^{c}$ Université Pierre et Marie Curie Paris 6, AP-HP, Groupe Pitié-Salpétrière, Paris, France.

Received for publication July 9, 2008; revisions received Sept 2, 2008; accepted for publication Sept 19, 2008.

Address for reprints: Pascal Leprince, MD, $\mathrm{PhD}$, Service de Chirurgie Thoracique et Cardiovasculaire, Groupe Pitié-Salpétrière, Institut de Cardiologie, 47-83 Boulevard de l'hôpital, 75013 Paris, France (E-mail: pascal.leprince@psl.aphp.fr).

J Thorac Cardiovasc Surg 2009;137:194-7

$0022-5223 / \$ 36.00$

Copyright (C) 2009 by The American Association for Thoracic Surgery doi:10.1016/j.jtcvs.2008.09.051 was then selected as a first-line treatment to allow better resource allocation. Because some of these patients had FM, we are now able to compare the efficacy and usefulness of ECMO versus the BIVAD in the setting of this acute disease.

\section{MATERIALS AND METHODS}

Between March 2001 and May 2006, 11 consecutive patients underwent mechanical cardiac support for FM. Five patients (group I) received a pneumatic paracorporeal BIVAD (Thoratec, Pleasanton, Calif). The 6 following patients (group II) received ECMO with the Jostra Rota Flow pump and the Quadrox Jostra D oxygenator (Maquet Cardiopulmonary AG, Hirrlingen, Germany). The ECMO device was implanted with femorofemoral cannulation and reperfusion of the superficial femoral artery with a femoral Seldicath connected in derivation on the arterial line (Figure 1).

As shown in Table 1, both groups were similar at clinical presentation. The APACHE II score did not show any difference between both groups ( $11 \pm 9$ for group I vs $24 \pm 18$ for group II), but there was a trend toward a higher score in group II patients. This means that even if the difference between groups was not significant, we observed a tendency for group II patients to be sicker.

All BIVADs were managed as previously described. ${ }^{3}$

ECMO devices were implanted on local (for 2 patients) and general (for 2 other patients) anesthesia at La Pitié's cardiac surgery department. The remaining 2 ECMO devices were installed in a primary care hospital ICU by the La Pitié's Circulatory Assistance Mobile Unit in unstable nontransferable patients. Those patients were secondarily transferred on ECMO at $\mathrm{La}$ Pitié's Hospital. Only 1 patient was admitted with an intra-aortic balloon counterpulsation (IABCP).

ECMO hemodynamic daily evaluation includes arterial pressure waveform assessment of occurrence of pulsatile blood flow and mean arterial 


\section{Abbreviations and Acronyms \\ BIVAD $=$ biventricular assist device \\ ECLS = extracorporal life support \\ $\mathrm{ECMO}=$ extracorporeal membrane oxygenation \\ $\mathrm{FM}=$ fulminant myocarditis \\ IABCP $=$ intra-aortic balloon counterpulsation \\ $\mathrm{RBCU}=$ red blood cell unit}

pressure level and transthoracic echocardiography, transesophageal echocardiography, or both. Pump speed is adjusted to achieve an extracorporeal blood flow of 4 to $7 \mathrm{~L} / \mathrm{min}$. Supportive care (volume expansion, catecholamines, or both) is based on the results of these repeated hemodynamic evaluations. Pharmacologic therapy (eg, intravenous immunoglobulins or corticosteroids) to facilitate myocardial healing were never used. IABCP was never required during assistance. Anticoagulation is achieved with unfractionated heparin to obtain an anti-Xa activity of 0.2 to $0.5 \mathrm{UI} / \mathrm{mL}$. In addition, patients with platelet counts of greater than $100 \mathrm{Giga} / \mathrm{L}$ receive $100 \mathrm{mg}$ of aspirin per day.

Postoperative care is performed for all patients in the intensive care unit. Weaning of BIVAD is performed as described by Slaughter et al. ${ }^{4}$

Concerning weaning of ECMO, myocardial recovery is assessed on the basis of several criteria: recovery of pulsatile blood flow, demonstration of a significant systolic heart function on echocardiographic analysis, and acceptable blood oxygenation. In these conditions an ECMO weaning trial is undertaken by progressively reducing the pump flow to less than $1.5 \mathrm{~L} /$ min and then by clamping both the venous and arterial lines of the circuit. The results of the weaning trial are considered favorable if after 2 minutes left ventricular ejection fraction remains at greater than $35 \%$ to $40 \%$ and aortic blood flow time-velocity integral remains greater than $14 \mathrm{~cm}$; however, ECMO pump flow is always restored for another 24 hours at $1.5 \mathrm{~L} /$ min. Finally, if the patient's hemodynamic status remains stable during this period, the ECMO device is removed.

\section{RESULTS}

Mean time of assistance from implantation to weaning was $21 \pm 5$ days in group I versus $13 \pm 4$ days in group II.

One patient died in each group. In group I the patient was a woman who underwent 45 minutes of resuscitation by means of external cardiac massage before implantation of the BIVAD. Death occurred after 18 days during support because of multiorgan failure. In group II the patient who was transferred at La Pitié under IABCP still showed an unstable hemodynamic status on femorofemoral ECMO. Then at day 10 she required intrathoracic ECMO implantation to produce a better flow associated with a pulmonary artery cannula to better unload the pulmonary vascular bed. At day 17 , decreasing outflow motivated switch to a BIVAD, which permitted recovery of hemodynamic status. Unfortunately, she died of tamponade at day 45 .

Other patients were weaned from mechanical circulatory support and were discharged home alive. In both groups no transplantations were required. Left ventricular function finally improved identically in both groups: $45 \%$ at weaning and $65 \%$ to $75 \%$ at 6 months' follow-up.

Mean flow was $5.4 \pm 0.7 \mathrm{~L} / \min \left(3.3 \pm 0.5 \mathrm{~L} \cdot \mathrm{min}^{-1} \cdot \mathrm{m}^{-2}\right)$ in group I versus $4.8 \pm 0.4 \mathrm{~L} / \min \left(2.5 \pm 0.7 \mathrm{~L} \cdot \mathrm{min}^{-1} \cdot \mathrm{m}^{-2}\right)$

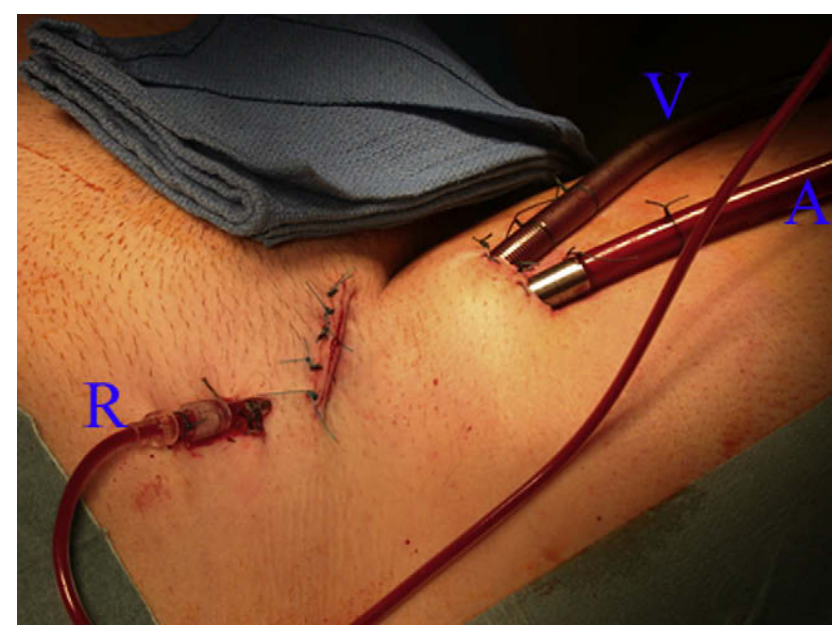

FIGURE 1. Representation of the femorofemoral ECMO circuit. $A$, Arterial line (using a $15 \mathrm{~F}-19 \mathrm{~F}$ cannula inserted in a common femoral artery); $V$, venous line (using a 19F-23F cannula inserted in the femoral vein); $R$, reperfusion of the superficial femoral artery with a femoral Seldicath connected in derivation on an arterial line (using a 5F 11-cm-long catheter). The $\mathrm{A}$ and $\mathrm{R}$ lines are crossed before respective arterial cannulations.

in group II. However, 2 patients in group II presented with a low outflow requiring therapeutic modifications. The first patient described above eventually died. The second patient with low flow had transient improvement when moving the venous cannula, but at day 5 , because of worsening of pulmonary edema, images observed on chest x-ray films, and persistent low flow $(3550 \mathrm{~L} / \mathrm{min})$, he underwent intrathoracic ECMO device implantation. Immediately, the patient had a satisfactory flow at $5900 \mathrm{~L} / \mathrm{min}$ for $4500 \mathrm{rpm}$ and quickly recovered his ventricular function. The ECMO device was removed at day 13 .

Figure 2 shows the evolution of plasmatic creatinine, total bilirubin, and transaminases in both groups: there was no significant difference before implantation; however, it is obvious that immediately after implantation of the BIVAD, group I patients experienced an initial phase of worsening before improvement. On the other hand, in group II patients implantation of ECMO was immediately followed by renal

TABLE 1. Clinical presentation of BIVAD group patients (group I) and ECMO group patients (group II)

\begin{tabular}{lccc}
\hline & Group I $(\mathbf{n}=\mathbf{5})$ & Group II $(\mathbf{n}=\mathbf{6})$ & $\boldsymbol{P}$ value \\
\hline Sex (male/female) & $2 / 3$ & $3 / 3$ & NS \\
Age (y) & $32 \pm 2$ & $40 \pm 4$ & NS \\
Ejection fraction & $33 \% \pm 8 \%$ & $18 \% \pm 4 \%$ & NS \\
$\quad($ left ventricle) & & & \\
Creatininemia (mg/L) & $19.5 \pm 7$ & $13.2 \pm 3$ & NS \\
Total bilirubinemia (mg/L) & $8 \pm 2$ & $23 \pm 6$ & NS \\
APACHE II score & $11 \pm 9$ & $24 \pm 18$ & NS \\
\hline
\end{tabular}

$B I V A D$, Biventricular assist device; $E C M O$, extracorporeal membrane oxygenation, NS, not significant. 

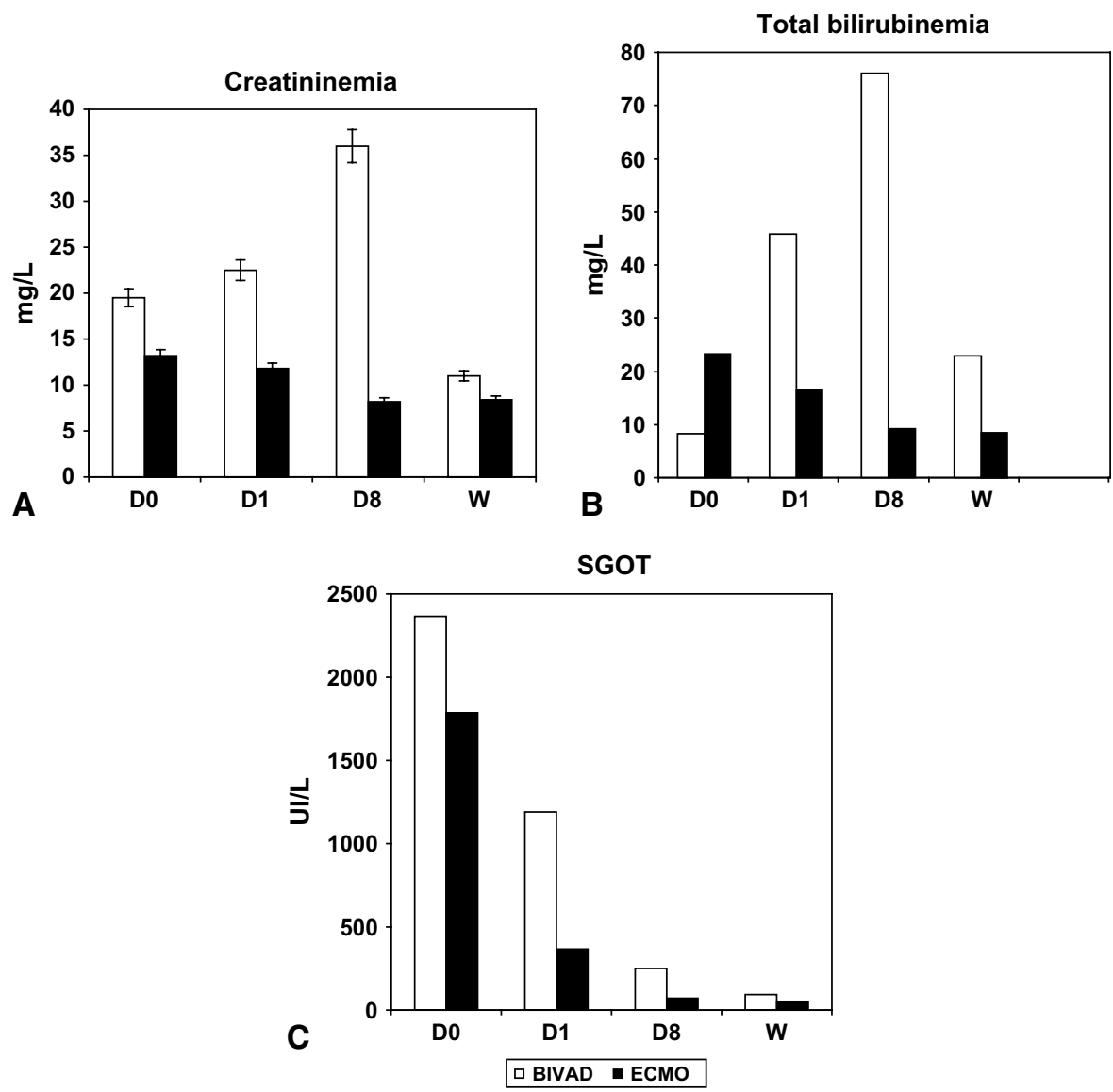

FIGURE 2. Graphics showing evolutions of renal (creatininemia, A) and hepatic (total bilirubinemia, B; aspartate aminotransferase [SGOT], C) functions in both groups: ECMO is shown in black, and BIVAD is shown in white. D0, Day 0 after implantation; D1, D1 after implantation; D8, D8 after implantation; $W$, weaning; $B I V A D$, biventricular assist device; $E C M O$, extracorporeal membrane oxygenation.

and hepatic function recovery. Even transaminase values decreased faster in group II than in group I. Moreover, this period of adaptation with a BIVAD might explain why, concerning inotropic support, the whole of group I still required noradrenaline after 48 hours of assistance versus one third of patients in group II.

Mean rate of red blood cell unit (RBCU) transfusion were statistically different between groups: $22 \pm 5 \mathrm{RBCU}$ per patient in group I versus $7 \pm 4 \mathrm{RBCU}$ per patient in group II $(P=.03)$. This reflects the fact that the re-exploration rate for hemostasis was lower in the myocarditis group supported by ECMO. Concerning infectious complications, all patients from group I had orotracheal intubation and finally presented with pneumonia (Haemophilus influenzae was most frequently found). Two of them had septicemia. On the other hand, the 3 patients in group II who received ECMO under local anesthesia (ie, without intubation) never had pulmonary infection (only $66 \%$ of group II patients had pneumonia). Another patient in group II had an infection of his cannulas. At that time, he showed a sufficient recovery to undergo ECMO explantation (left ventricular ejection fraction, $40 \%$ ) and was finally discharged at day 38 .
No neurologic complications were noted in both groups.

The 1-year survival of patients weaned from BIVAD and ECMO was 4 of 4 and 4 of 5, respectively. The patient who died in group II committed suicide 3 months after discharge home.

\section{DISCUSSION}

This is the first comparative study between ECMO and a BIVAD in adult FM carried out within the same surgical team.

In 2005, Chen and colleagues ${ }^{5,6}$ published their own experience of ECMO in patients with FM and compared it with data on use of BIVADs from the literature. They described a group of 15 patients for whom the mean time of assistance on ECMO was $5.7 \pm 3.1$; the neurologic complication rate was $6.7 \%$, and the re-exploration rate for hemostasis was $8.9 \%$. Global survival was $73.3 \%$. They concluded their results were better than those published on BIVADs in the literature and considered ECMO to be the first-line mechanical circulatory support treatment in patients with FM with profound shock when IABCP is inadequate or infeasible. 
Acker, ${ }^{2}$ in 2001, reviewed the literature comparing different types of mechanical support in adults with FM: ECMO, left ventricular assist device (Abiomed, Danvers, Mass; Thoratec; Thermo Cardiosystems, Woburn, Mass; and Novacor, World Heart, Inc, Oakland, Calif), and BIVAD (Abiomed and Thoratec). The highest survival rate was reported with the BIVAD, leading to either recovery or transplantation in $70 \%$ of the patients. In our series we report the same survival rate as Acker with both the BIVAD and ECMO systems; one can assume that this is in part due to the fact that we could achieve the same blood flow. Moreover, we found a significantly lower rate of RBCU transfusions associated with ECMO. Furthermore, duration of assistance, infectious complication rate (especially in patients who has an ECMO device installed after achieving local anesthesia), and renal and hepatic dysfunctions tended to be less in our ECMO group patients.

The short duration of support in patients undergoing ECMO can be explained by the fact that it is easier to make a decision to remove an ECMO device than a BIVAD.

Furthermore, femorofemoral ECMO can be set up easily outside of a cardiac surgery center (after achievement of local anesthesia or not) and allows secondary transfer, as we experienced for our 2 patients. This ability to transfer was already described by McBride and associates ${ }^{7}$ in 2000, who underlined that patients could be moved between clinical centers with acceptable risks. This technique allows supporting patients who would have died otherwise. Moreover, because ECMO can be set up under local anesthesia and can provide simultaneous oxygenation, orotracheal intubation is not necessarily required. This permits better pulmonary outcome: no pneumonia was observed in patients with ECMO devices implanted after achievement of local anesthesia versus $100 \%$ of patients who underwent implantation of a mechanical support device under orotracheal intubation (BIVAD or ECMO).

Finally, in case of persistent low outflow with femorofemoral ECMO, we think, in opposition to some authors, ${ }^{8}$ that shifting to a central ECMO system is more simple and less invasive than shifting to a BIVAD. Finaly ECMO is less costly (Disposable material is 24 times cheaper for ECMO in comparison to BIVAD in our experience).

\section{CONCLUSION}

ECMO is as efficient as a BIVAD in supporting adult patients with FM related to cardiogenic shock. ECMO facilitates quick recovery of renal and hepatic function. Moreover, it shows several advantages: red blood cell saving, possibility of local anesthesia for set up and removal, mobility of surgical teams for installation, and safety of secondary transfer. In conclusion, femorofemoral ECMO is the best first-line treatment in FM in adults, with central ECMO as a second-line treatment.

\section{References}

1. Farrar DJ, Holman WR, McBride LR, Kormos RL, Icenogle TB, Hendry PJ, et al Long-term follow-up of Thoratec ventricular assist device bridge-to-recovery patients successfully removed from support after recovery of ventricular function. J Heart Lung Transplant. 2002;21:516-21.

2. Acker MA. Mechanical circulatory support for patients with acute-fulminant myocarditis. Ann Thorac Surg. 2001;71(suppl):S73-6, S82-5.

3. Leprince P, Combes A, Bonnet N, Ouattara A, Luyt CE, Theodore P, et al. Circulatory support for fulminant myocarditis: consideration for implantation, weaning and explantation. Eur J Cardiothorac Surg. 2003;24:399-403.

4. Slaughter MS, Silver MA, Farrar DJ, Tatooles AJ, Pappas PS. A new method of monitoring recovery and weaning the Thoratec left ventricular assist device. Ann Thorac Surg. 2001;71:215-8.

5. Chen YS, Yu HY, Huang SC, Chiu KM, Lin TY, Lai LP, et al. Experience and result of extracorporeal membrane oxygenation in treating fulminant myocarditis with shock: what mechanical support should be considered first? J Heart Lung Transplant. 2005;24:81-7.

6. Chen YS, Wang MJ, Chou NK, Han YY, Chiu IS, Lin FY, et al. Rescue for acute myocarditis with shock by extracorporeal membrane oxygenation. Ann Thorac Surg. 1999;68:2220-4

7. McBride LR, Lowdermilk GA, Fiore AC, Moroney DA, Brannan JA, Swartz MT Transfer of patients receiving advanced mechanical circulatory support. $J$ Thorac Cardiovasc Surg. 2000;119:1015-20.

8. Pennington DG, Smedira NG, Samuels LE, Acker MA, Curtis JJ, Pagani FD. Mechanical circulatory support for acute heart failure. Ann Thorac Surg. 2001; 71(suppl):S56-9, S82-5. 